\title{
Efficacy of metoclopramide and dexamethasone for postoperative nausea and vomiting: a double-blind clinical trial
}

M. Entezariasl, M. Khoshbaten, ${ }^{2}$ K. Isazadehfar ${ }^{1}$ and G. Akhavanakbari ${ }^{1}$

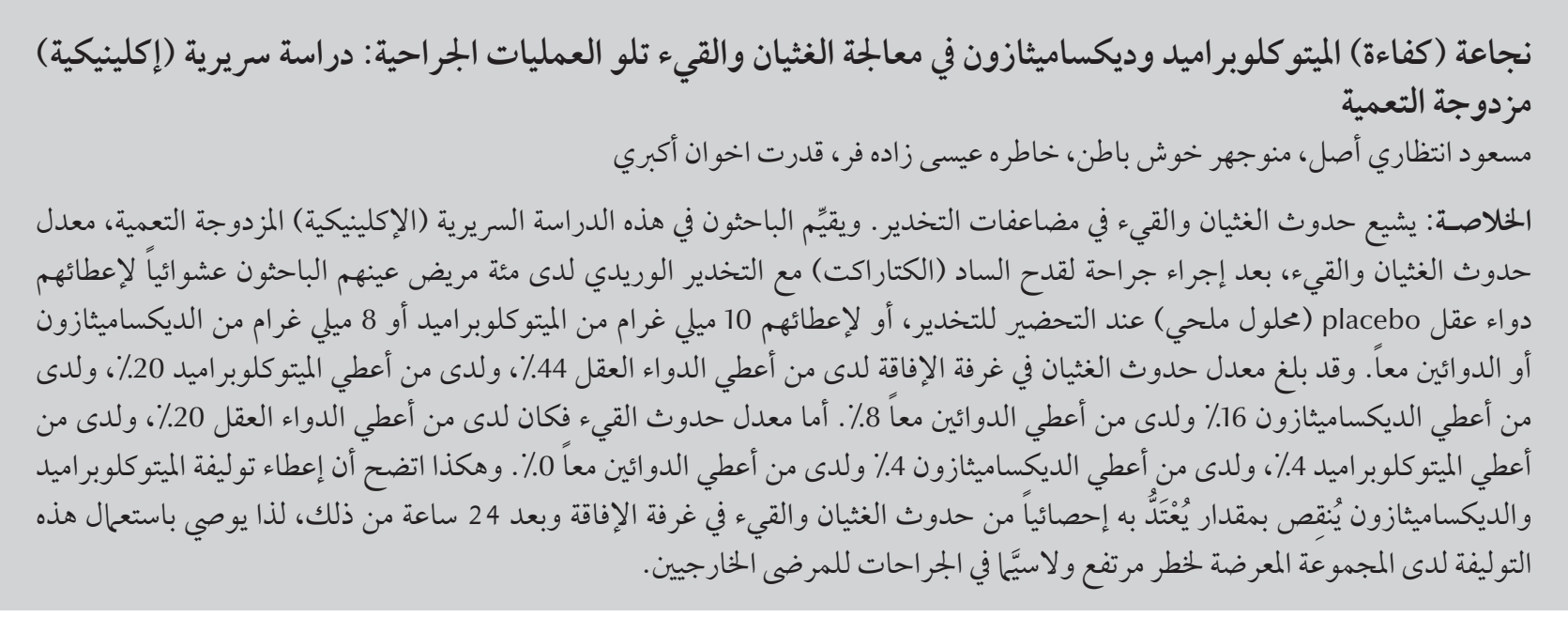

ABSTRACT Postoperative nausea and vomiting are common complications of anaesthesia. This double-blind clinical trial assessed the incidence of nausea and vomiting after cataract surgery with intravenous anaesthesia in 100 patients randomly assigned to preinduction placebo (saline), metoclopramide (10 $\mathrm{mg}$ ), dexamethasone ( $8 \mathrm{mg}$ ) or the 2 drugs combined. The incidence of nausea in the recovery room was $44 \%$ with placebo, 20\% with metoclopramide, $16 \%$ with dexamethasone and $8 \%$ with the combination. The incidence of vomiting was $20 \%$, $4 \%, 4 \%$ and $0 \%$ respectively in the 4 groups. Metoclopramide plus dexamethasone combination significantly decreased nausea and vomiting both in the recovery room and 24 hours afterwards and is recommended for high-risk groups, especially in outpatient surgeries.

Efficacité du métoclopramide et de la dexaméthasone sur les nausées et vomissements postopératoires : une étude clinique en double aveugle

RÉSUMÉ Les nausées et vomissements postopératoires sont des complications courantes de l'anesthésie. Cette étude clinique en double aveugle évaluait l'incidence des nausées et des vomissements après une chirurgie de la cataracte avec anesthésie par voie intraveineuse chez 100 patients auxquels un placebo (eau saline), du métoclopramide (10 mg), de la dexaméthasone $(8 \mathrm{mg}$ ) ou les deux médicaments associés avaient été administrés de manière randomisée avant l'opération. L'incidence des nausées en salle de réveil était de $44 \%$ avec le placebo, $20 \%$ avec le métoclopramide, $16 \%$ avec la dexaméthasone et $8 \%$ avec l'association des deux médicaments. L'incidence des vomissements était de $20 \%, 4 \%$, $4 \%$ et $0 \%$, respectivement, dans les quatre groupes. L'association du métoclopramide et de la dexaméthasone a considérablement réduit les nausées et vomissements, non seulement en salle de réveil mais également dans les 24 heures qui suivent, et est recommandée pour les groupes à haut risque, notamment pour les patients opérés en ambulatoire. 


\section{Introduction}

Postoperative nausea and vomiting (PONV) is one of the most common complications of anaesthesia [1]. Despite significant improvements in therapeutics and anaesthesia techniques, the rate of this complication still remains high. PONV afflicts around one-third of patients undergoing operation with general anaesthesia [2], and can lead to wound dehiscence, bleeding, aspiration of gastric contents, water and electrolyte abnormalities, prolonged hospitalization, rehospitalization and patients' low satisfaction with postoperative care [3]. It is so unpleasant that most patients would prefer to experience postoperative pain rather than nausea and vomiting [4].

Occurrence of PONV is influenced by various factors such as duration of anaesthesia, type of surgery, use of narcotics, patient's age and sex, and history of PONV, motion sickness or smoking [4]. Cataract surgery, however, has not been reported to increase postoperative nausea and vomiting. Evidence shows that PONV may be prevented by using prophylactic injection of certain drugs [5]. Dexamethasone and metoclopramide are commonly used separately for this purpose, and most studies have demonstrated their efficacy in decreasing PONV [6-8]. In the current study, the effect of preoperative injection of dexamethasone, metoclopramide and their combination on PONV was investigated.

\section{Methods}

The study was a double-blind clinical trial. The study group was 100 patients referred to Alavi Hospital in Ardebil (northwest of Islamic Republic of Iran) for cataract surgery under general anaesthesia who met the American Society of Anesthesiologists' physical status classification class 1 (normal healthy patient) or 2 (patient with mild systemic disease).
The sample size was calculated based on probability of reducing PONV by $40 \%$, with $\alpha=0.05$ and $\beta=20 \%$. The baseline exclusion criteria were: suffering from diabetes mellitus or other underlying disorders, use of antiemetics during the past 24 hours and a positive history of motion sickness or PONV.

Patients were enrolled 1 hour before going to the operating room and only if they agreed to participate in the study after it had been fully explained them and they signed an informed consent form. This was prepared by the ethical committee of Ardebil University of Medical Sciences and allowed participants to withdraw at any point in the study no explanation and without jeopardizing the quality of care they received.

The patients were randomly assigned by block randomization to one of 4 groups of 25 patients: placebo ( 2 $\mathrm{mL}$ normal saline); metoclopramide $(10 \mathrm{mg})$; dexamethasone $(8 \mathrm{mg})$; or metoclopramide plus dexamethasone $(10 \mathrm{mg} / 8 \mathrm{mg})$. All the treatments were given intravenously 1 minute before induction of anaesthesia by injection of fentanyl $(2 \mu \mathrm{g} / \mathrm{kg})$, propofol $(2 \mathrm{mg} /$ $\mathrm{kg})$ and atracurium $(0.5 \mathrm{mg} / \mathrm{kg})$. They were given by the anaesthetist who was unaware of the drug allocation. Following tracheal intubation, anaesthesia was continued with an infusion of propofol $(50 \mu \mathrm{g} / \mathrm{kg} / \mathrm{min})$ while the patient breathed a combination of $\mathrm{O}_{2}(50 \%)$ and $\mathrm{N}_{2} \mathrm{O}(50 \%)$. Local anaesthetics were not applied during surgery.

The duration of surgery was almost the same (i.e. range of 35-40 minutes) for all patients. Following surgery, patients were transferred to the recovery room, where the incidence of PONV and the frequency of those needing treatment for PONV were evaluated by nurses, who were blind to the patient's group as the drug administered was not recorded on the patient's anaesthesia chart. The occurrence of PONV was also recorded 24 hours following surgery. Nausea and vomiting were recorded by nurses as present or absent.
Pain intensity was assessed using a 10 $\mathrm{cm}$ visual analogue scale $(0=$ no pain to $10=$ most severe pain). Since pain after cataract surgery is relatively slight, patients did not receive further analgesic treatment after discharge. Any patient experiencing moderate to severe pain (score $\geq 5$ ) would receive $50 \mathrm{mg}$ pethidine and be ineligible to finish the study; however no cases were reported.

The data were analysed using SPSS, version 13.0. A series of 1-way analyses of variance were conducted to examine differences between the 4 groups with respect to parametric variables. If a significant difference was found, the Bonferroni $t$-test was used to detect intergroup differences. Categorical variables were analysed by using a series of $4 \times 2$ chi-squared tests to determine the differences between the 3 treatment groups versus placebo.

\section{Results}

A total of 100 patients were included in the final analysis. There were no significant differences between the background characteristics of patients in the 4 groups in terms of age, sex, duration of surgery or history of smoking (Table 1).

The incidence of nausea and vomiting in the recovery room and 24 hours after the operation is shown in Table 2. Patients in the metoclopramide, dexamethasone and combination groups had a lower incidence of nausea $(20 \%, 16 \%$ and $8 \%$ respectively) in the recovery room when compared with the placebo group (44\%). The incidence of vomiting in the recovery room was $4 \%, 4 \%$ and $0 \%$ respectively compared with $20 \%$ in the placebo group. Although both metoclopramide and dexamethasone separately were effective in reducing the symptoms of PONV, the difference was only statistically significant for the combination. Similar results were found after 24 hours (Table 2). 


\begin{tabular}{|c|c|c|c|c|c|}
\hline Variable & Placebo $(n=25)$ & $\begin{array}{l}\text { Metoclopramide } \\
\qquad(n=25)\end{array}$ & $\begin{array}{l}\text { Dexamethasone } \\
\qquad(n=25)\end{array}$ & $\begin{array}{c}\text { Metoclopramide }+ \\
\text { dexamethasone }(n= \\
25)\end{array}$ & $P$-value ${ }^{a}$ \\
\hline Age [mean (SD) years] ${ }^{\mathrm{b}}$ & $67.1(9.3)$ & $61.5(10.1)$ & $65.9(11.4)$ & $71(5.9)$ & 0.80 \\
\hline \multicolumn{6}{|l|}{ Sex $[$ no. $(\%)]$} \\
\hline Female & $13(52)$ & $10(40)$ & $11(44)$ & $14(56)$ & \multirow{2}{*}{0.70} \\
\hline Male & $12(48)$ & $15(60)$ & $14(56)$ & $11(44)$ & \\
\hline $\begin{array}{l}\text { Duration of surgery } \\
\text { [mean (SD) min] }\end{array}$ & $36.2(2.3)$ & $38.5(1.8)$ & $35.4(1.1)$ & $37.2(2.4)$ & 0.65 \\
\hline $\begin{array}{l}\text { History of smoking } \\
\text { [no. (\%)] }\end{array}$ & $3(12)$ & $5(20)$ & $3(12)$ & $3(12)$ & 0.09 \\
\hline
\end{tabular}

${ }^{a}$ Chi-squared test and ANOVA; ${ }^{b}$ Range 50 to 80 years. $S D=$ standard deviation .

There was no significant difference in the incidence of nausea and vomiting between males and females in the 4 study groups (data not shown, $P=$ 0.76).

The intensity of postoperative pain was relatively minor, with patients in the 4 groups reporting similar low/median pain scores: placebo 1.7 ; metoclopramide 2.3; dexamethasone 2.4; combination 1.9. Furthermore, when compared with the placebo group, no significant difference was observed in any of the 3 treatment groups (i.e. metoclopramide, dexamethasone or combination) in terms of the frequency of need for postoperative analgesics.

\section{Discussion}

PONV is still among the most common and troublesome complications of surgery, causing delays in patient discharge from hospital, especially in outpatient surgeries. Therefore, therapeutic strategies preventing this complication are of utmost importance [9]. Replacing nitrous oxide with intravenous propofol has reduced, but not eliminated, the incidence of PONV $[10,11]$. In the current study, the preventive effect of metoclopramide, dexamethasone and their combination in decreasing PONV in elderly people undergoing cataract surgery was investigated. The results of this study showed that although patients given metoclopramide or dexamethasone alone had a lower incidence of PONV, the effect was not statistically significant whereas their combined use had a significant effect. The incidence of nausea with metoclopramide plus dexamethasone was $8 \%$ versus $44 \%$ with placebo and the incidence of vomiting was $0 \%$ versus $20 \%$ with placebo. This underlines the beneficial effect of combined use of these 2 drugs.

Some previous placebo-controlled studies have also demonstrated the preventive effect of preoperative use of dexamethasone (especially in combination with metoclopramide) on PONV. In 204 patients undergoing lumbar disc surgery, Wallenborn et al. showed that while the incidence of nausea and vomiting was $35.8 \%$ in the placebo group, the preoperative use of combined metoclopramide and dexamethasone decreased the incidence of postoperative nausea to $10 \%$ and vomiting to $3 \%$ [12]. In another study by Feo et al. on laparoscopic surgery patients, the incidence of nausea and vomiting was $46 \%$ in the placebo group and $14 \%$ in the dexamethasone group [13]. Laiq et al., in a study on 100 patients undergoing gynaecological surgery, found that nausea and vomiting decreased from $30 \%$ and $24 \%$

\begin{tabular}{|c|c|c|c|c|c|c|c|}
\hline \multirow[t]{2}{*}{ Group } & \multirow{2}{*}{$\begin{array}{c}\text { Placebo }(n= \\
25) \\
\%\end{array}$} & \multicolumn{2}{|c|}{ Metoclopramide $(n=25)$} & \multicolumn{2}{|c|}{ Dexamethasone $(n=25)$} & \multicolumn{2}{|c|}{$\begin{array}{c}\text { Metoclopramide }+ \\
\text { dexamethasone }(n=25)\end{array}$} \\
\hline & & $\%$ & $P$-value ${ }^{a}$ & $\%$ & $P$-value ${ }^{a}$ & $\%$ & $P$-value ${ }^{a}$ \\
\hline \multicolumn{8}{|c|}{ In recovery room } \\
\hline Nausea & 44 & 20 & 0.72 & 16 & 0.65 & 8 & 0.01 \\
\hline Vomiting & 20 & 4 & 0.55 & 4 & 0.55 & 0 & 0.02 \\
\hline \multicolumn{8}{|c|}{ After 24 hours } \\
\hline Nausea & 52 & 20 & 0.68 & 20 & 0.68 & 8 & 0.008 \\
\hline Vomiting & 20 & 4 & 0.55 & 4 & 0.55 & 0 & 0.02 \\
\hline
\end{tabular}

${ }^{a}$ Compared with the placebo group by the chi-squared test. 
respectively with placebo to $20 \%$ and $6 \%$ with dexamethasone [14]. According to Huang et al., $5 \mathrm{mg}$ dexamethasone significantly decreased the incidence of PONV from $70 \%$ to $28 \%$ [15], while Wang et al. showed dexamethasone decreased nausea and vomiting from 63\% to $23 \%$ in patients having laparoscopic cholecystectomy [16].

In contrast, Chekman et al., comparing the effect of dexamethasone and metoclopramide (injected 10 minutes before anaesthesia) in 45 patients divided into 3 groups, showed that
PONV incidence was not significantly different between the dexamethasone and metoclopramide groups [17]. The difference between our results and theirs was probably due to the time of drug injection, since its effect on PONV might be diminished due to the short half-life of the drug. The limited number of patients in Chekman's study was their main limitation.

Our study has some limitations that might have influenced the findings. First, our sample size was small. Second, the study was conducted only in patients undergoing cataract surgery. Third, it was conducted only in older patients. However, our study protocol was a strong point.

In conclusion, although prophylactic injection of $10 \mathrm{mg}$ metoclopramide or $8 \mathrm{mg}$ dexamethasone separately can decrease the incidence of PONV, the combined use of these drugs has a more marked and significant effect. In view of the low cost of these drugs, their combined prophylactic use is recommended in the groups at risk for PONV, especially in outpatient surgeries.

\section{References}

1. Golembiewski J, Gernin E, Chopra T. Prevention and treatment of postoperative nausea and vomiting. American journal of health-system pharmacy, 2005, 62(12):1247-60.

2. Apfel CC et al. A factorial trial of six interventions for the prevention of postoperative nausea and vomiting. New England journal of medicine, 2004, 350(24):2441-51.

3. $\mathrm{Ku} \mathrm{CM}$, Ong BC. Postoperative nausea and vomiting: a review of current literature. Singapore medical journal, 2003, 44(7):366-74.

4. Apfel CC, Roewer N. Postoperative nausea and vomiting. Anesthesia, 2004, 53(4):377-89.

5. Tatic $M$ et al. Postoperativna muka i povracanje [Postoperative nausea and vomiting]. Medicinski pregled, 2003, 56(9-10):431-5.

6. Langer R. Postoperative nausea and vomiting. Educational synopses in anaesthesiology and critical care medicine, 1996, 1(3) (http://anestit.unipa.it/gta/nausea.html, accessed 29 August 2009).

7. Habib AS, Gan TJ. Evidence-based management of postoperative nausea and vomiting: a review. Canadian journal of anaesthesia, 2004, 51(4):283-5.

8. Henzi I, Walder B, Tramèr MR. Dexamethasone for the prevention of postoperative nausea and vomiting: a quantitative systematic review. Anesthesia and analgesia, 2000, 90:186-91.

9. Garrett $\mathrm{K}$ et al. Managing nausea and vomiting. Critical care nurse, 2003, 23:31-50.

10. Sneyd JR et al. A meta-analysis of nausea and vomiting following maintenance of anaesthesia with propofol or inha- lational agents. European journal of anaesthesiology, 1998, 15(4):433-45.

11. Yavosgo R et al. Propofol-nitrous oxide versus sevofluranenitrous oxide for strabismus surgery in children. Paediatric anaesthesia, 1999, 9:495-9.

12. Wallenborn J et al. Metoclopramid und Dexamethason zur Prophylaxe von postoperativer Ubelkeit und Erbrechen nach balancierter Anasthesie [Metoclopramide and dexamethasone in prevention of postoperative nausea and vomiting after inhalation anesthesia]. Anästhesiologie, Intensivmedizin, Notfallmedizin, Schmerztherapie, 2003, 38(11):695-704.

13. Feo CV et al. Randomized clinical trial of the effect of postoperative dexamethasone on nausea and vomiting after laparoscopic cholecystectomy. British journal of surgery, 2006, 93(3):295-9.

14. Laiq N et al. Dexamethasone as antiemetic during gynaecological laparoscopic surgery. Journal of the College of Physicians and Surgeons-Pakistan, 2005, 15(12):778-81.

15. Huang JC et al. Low dose dexamethasone effectively prevents postoperative nausea and vomiting after ambulatory laparoscopic surgery. Canadian journal of anaesthesia, 2001, 48(10):973-7.

16. Wang J et al. Dexamethasone reduces nausea and vomiting after laparoscopic cholecystectomy. British journal of anaesthesia, 1999, 83(5):772-5.

17. Ekmen $\mathrm{N}$ et al. Comparison of the effects of dexamethasone and metoclopramide on postoperative nausea and vomiting. Erciyes medical journal, 2003, 25(3):137-43. 